Journal of ISMAC (2019)

Vol.01/ No. 03

Pages: 137-146

http://irojournals.com/iroismac/

DOI: https://doi.org/10.36548/jismac.2019.3.001

\title{
SECURE AND SUSTAINABLE SMART GRID FRAME WORK USING THE CLOUD COMPUTING
}

\author{
Dr. S. Smys, \\ Professor, Department of Computer Science and Engineering, \\ RVS Technical Campus, \\ Coimbatore, India. \\ Email: $\underline{\text { smys375@gmail.com }}$ \\ Dr. Abul Bashar, \\ Department of Computer Engineering, \\ Prince Mohammad Bin Fahd University, \\ Al Khobar, Kingdom of Saudi Arabia. \\ Email: abashar@pmu.edu.sa \\ Dr. Haoxiang Wang, \\ Department of Electrical and Computer Engineering, \\ Cornell University, \\ Ithaca, USA. \\ Email: wanghaoxiang1102@hotmail.com
}

\begin{abstract}
The smart grid developments turning out to a promising technology for the two way communication of the electricity and the information are becoming more prominent in the present scenario due to the increasing demands in the power requirements. The smart grid utilizing the modern communication and the computing infrastructure makes this possible. This utilization of the modern communication and the computing systems make them even prone to the vulnerabilities, mishandlings and the miscommunications and necessary for a complex frame work for managing of the power distribution and generation to make them sustainable. So the paper proposes the cloud computing for the proper management and the protection of the smart grids to make them more secure against threats and sustainable by reducing the $\mathrm{Co}_{2}$ emission by the perfect management. The validation of the smart grid frame work using cloud computing by monitoring the power distribution, management and the security achieved over multiple usages show the enhanced power management and the security services provided by the cloud for the smart grid.
\end{abstract}

Keywords: Smart grid, Cloud computing, Power management, Protection, Sustainability

\section{INTRODUCTION}

The conventional method of electricity distribution, conveyance, generation and the control has been followed for the past hundred years. The conventional power grids were very convenient and sufficient as the power requirements were also very meager. But nowadays the requirement level for the power consumption has changed due to the emergence 
Journal of ISMAC (2019)

Vol.01/ No. 03

Pages: $137-146$

http://irojournals.com/iroismac/

DOI: https://doi.org/10.36548/jismac.2019.3.001

of many modern equipment's and systems. This leads to more power requirements as well as an efficient management of the power distribution as the conventional methods find it difficult to manage with the distribution of the electricity according to the increasing energy demand, losses and the illegal utilization. The fig .1 below shows the conventional power grid that is comprised of the power generating stations, transmission infrastructures, distribution lines and the distribution networks.

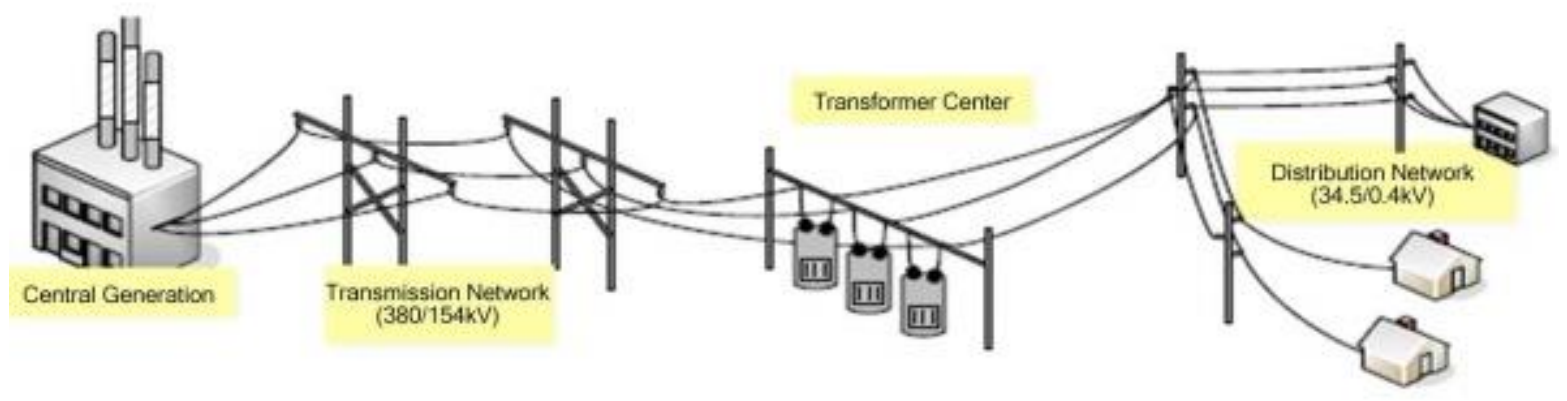

Fig.1 Conventional Grid [6]

The grid usually refers to the basic electricity system that essentially deals with the generation of the electricity, transmission, distribution, and its control. The challenge faced by the traditional grid paves the necessity for the intelligent grid that is smart enough in handling the requirements of the today's world. As shown in the fig. 1 the conventional electricity systems were regularized for carrying the electricity generated from certain central generators of electricity to its users and would be billed bimonthly or every month based on the usage, thus providing a single way communication. But the smart grid that is intelligent unlike the conventional ones allows a two way communication of the power and the information's leading to energy delivery network that is built with the automation and the distributed nature. The fig. 2 below gives the smart grid frame work that effectively conveys and the information in the two ways. They are constructed with the capacity of responding to any events such as transmission, generation distribution, rerouting of the power delivery on cases of the transformer failures that occurs anywhere in the grid [1] 
Journal of ISMAC (2019)

Vol.01/ No. 03

Pages: $137-146$

http://irojournals.com/iroismac/

DOI: https://doi.org/10.36548/jismac.2019.3.001

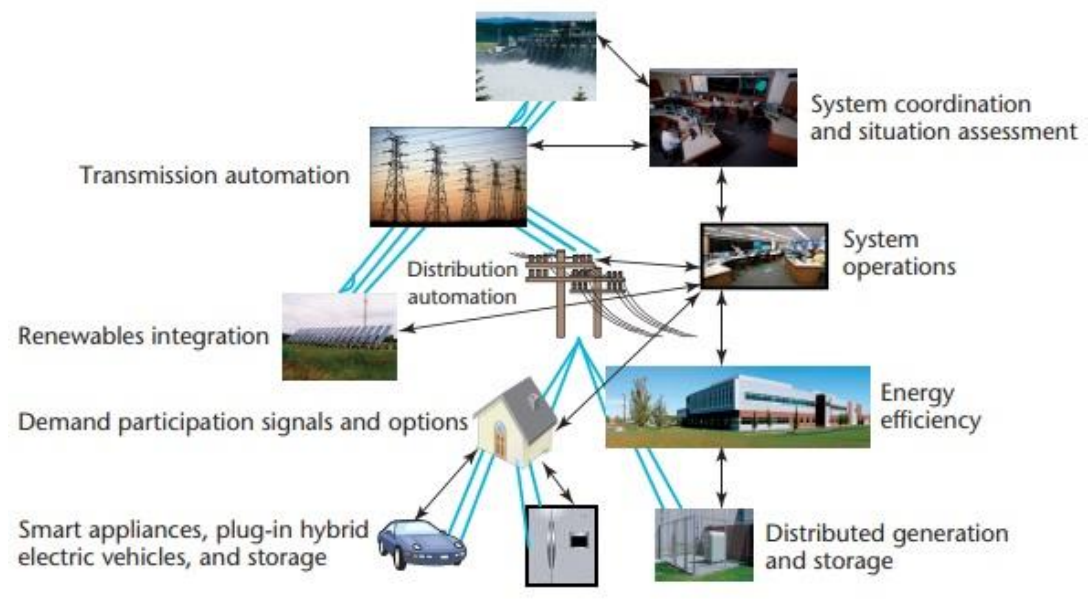

Fig.2 Smart Grid Frame work [4]

The smart grids in order to provide with the well-developed infrastructure for the transmission of the energy, with the automated controlling utilizing the high power convertors, the modern communication systems, monitoring and the metering techniques for the energy requirements and the usage. This might necessitate a more complex infrastructure that is compatible for the larger dimensions of the smart grid [2]. In the present scenario the global power grids are shifting to the latest technologies due to the demand for the electricity even at houses [3] however these developments lead to the incurring of multitudes of risks in the communication and computer infrastructures that are tied along with the prevailing physical infrastructure causing vulnerabilities, alterations and the misuse.

So it becomes necessary for a smart infrastructure that could help in the perfect managing and securing of this smart grid with its power generation, transmission, monitoring, metering and information transmission thus providing a secure and a sustainable management.

So the paper proposes the cloud computing based smart grid frame work for effective management of the power generation and its usage, along with the security and sustainability reducing the enormous $\mathrm{Co}_{2}$ generation by the perfect management of the power production and distribution, and security measurers avoiding the vulnerabilities, miscommunication and misuse. 
Journal of ISMAC (2019)

Vol.01/ No. 03

Pages: $137-146$

http://irojournals.com/iroismac/

DOI: https://doi.org/10.36548/jismac.2019.3.001

The paper remaining is arranged with the 2.explaining the Related works, 3. With the proposed work describing the cloud computing managing and the security services of the smart grid. 4. Detailing the results in terms of better power management and the security for the smart grid. Conclusion in .5

\section{RELATED WORKS}

Fang, et al [1] the paper elaborates the smart infrastructure, management and the protection system that are associated with the smart grid in the survey, starting with the exploration of the energy, communication and the information subsystems that are smart along with the different objectives such the enhancing of the efficiency in the energy, describing the demand, utilization etc.

Gungor, et al [2] the author discusses the important issues related to the smart grid basically on the grounds of the information and the communication systems in order provide a clear view of the open issues, potential merits and the unresolved challenges of the smart grid.

McDaniel et al [3] the author details the emerging of the modern power grids with the two way communication, named as the smart grid. He also details the capability of the smart grid in terms of the monitoring, controlling and energy use prediction compared to the antique infrastructure of the traditional power grids.

Khurana et al [4] the paper describes the major approaching alterations, with the highlights of the security related issues that are associated with the infrastructure of the modernized power grid that are fully connected, providing a two way communication utilizing the digital communication system and the computer networks that more prone to vulnerabilities.

Amin et al [5] the challenges of the power grid of the north America and the efficient alternative to solve the problem of the power grid by shifting to a well-managed smart grid with an improved reliability, enhanced security, potentials for managing the higher demand.

Farhangi, et al [6] the author discusses the transformation in the business, organization and the technologies that have occurred due to the adoption of the smart grid concepts, methodologies and the system. 
Journal of ISMAC (2019)

Vol.01/ No. 03

Pages: $137-146$

http://irojournals.com/iroismac/

DOI: https://doi.org/10.36548/jismac.2019.3.001

Bayindir, et al [7] the author discusses the importance, efficiencies and the capabilities of the smart grid along with the necessity of transformations from the conventional to the smart grids. He summarizes the economical merits that could be achieved by with the data transmission using technological methods.

Tuballa et al [8] the author details the potentials and the importance of the smart grid, he explains how the smart grid has modified the electricity supply meeting all the requirements and the demands, along with the better alignment. The makes a clear statement of the features, characteristics, and the betterment achieved by the smart grid along with the challenges in the secured way of transmission and the issues in the perfect management.

Hayes et al [9] describes the details of the cloud computing he states "like the creatures of the earth being plucked to be placed as stars in the constellation. The data and the programs are being swept from the PC into a paradigm called cloud that holds a corporate server rooms installed in it" the author says that this new paradigm leads into a sophistication eliminating the need for the manual and individual recharges, maintenance, installation and ensuring full automation along with the digital storage that can be afforded for a long term with the reliability. He presents the cloud computing as the promising technology with the service provisioning based on the infrastructure, software and the platform.

Buyya et al [10] the paper presents few representatives cloud platforms that improve the market strategies, so the cloud computing paradigms for the market oriented resource allocation are addressed in the paper.

Zhang et al [11] the author elaborates the potentials and the cloud servicing utilizing the internet, he discusses the features of the cloud that make them very attractive among the business and the IT industries as it eliminates the need for the planning ahead for the provisioning and many other advantages as a survey, presenting the concepts, fundamentals, start of art implementations etc.

JoSEP et al [12] the author present s the view of the cloud computing by defining "the cloud computing as the long held dream of computing as the utility" he delivers the details on the cloud how effectively it could be used for providing the software as service, infrastructure as service platform as service, application as service providing a perfect management with reliability for all kinds of services provided.

\section{PROPOSED WORK}


Journal of ISMAC (2019)

Vol.01/ No. 03

Pages: $137-146$

http://irojournals.com/iroismac/

DOI: https://doi.org/10.36548/jismac.2019.3.001

The proposed work aims in developing a smart grid frame work that is efficient in the managing of the power distribution, transmission, the generation, meeting all the energy requirement based on the demand in the peak time and the normal time along with the reliability using the cloud computing.

\subsection{CHALLENGES IN SMART GRID}

Some of the challenges in the smart grid are

- Development and deploying computer and the communication infrastructure that is extensive.

- Entailment of defense supervisory system to effectively manage the huge set of information flow for enumerating the status of the system, its failures, the possible threats along with the suggestion of the remediation to be followed.

- Requirement of enhanced and a fine tuned command and control

- Perfect management in the automation of transmission, distribution, demand responses, storage.

- Protective measures against the vulnerabilities, threats, mishandlings, misuse and the miscommunications

All these challenges would lead to a designing of the complex infrastructure for the smart grids in managing and protecting its services. So in order to avoid the complex infrastructure and the cost in developing them, the smart grid is integrated to the cloud computing in the proposed methodology, to provide with the perfect management and the security as service required for the smart grid on pay per use.

\subsection{PROPOSED SECURE SUSTAINABLE SMART GRID USING CLOUD COMPUTING}


Journal of ISMAC (2019)

Vol.01/ No. 03

Pages: $137-146$

http://irojournals.com/iroismac/

DOI: https://doi.org/10.36548/jismac.2019.3.001

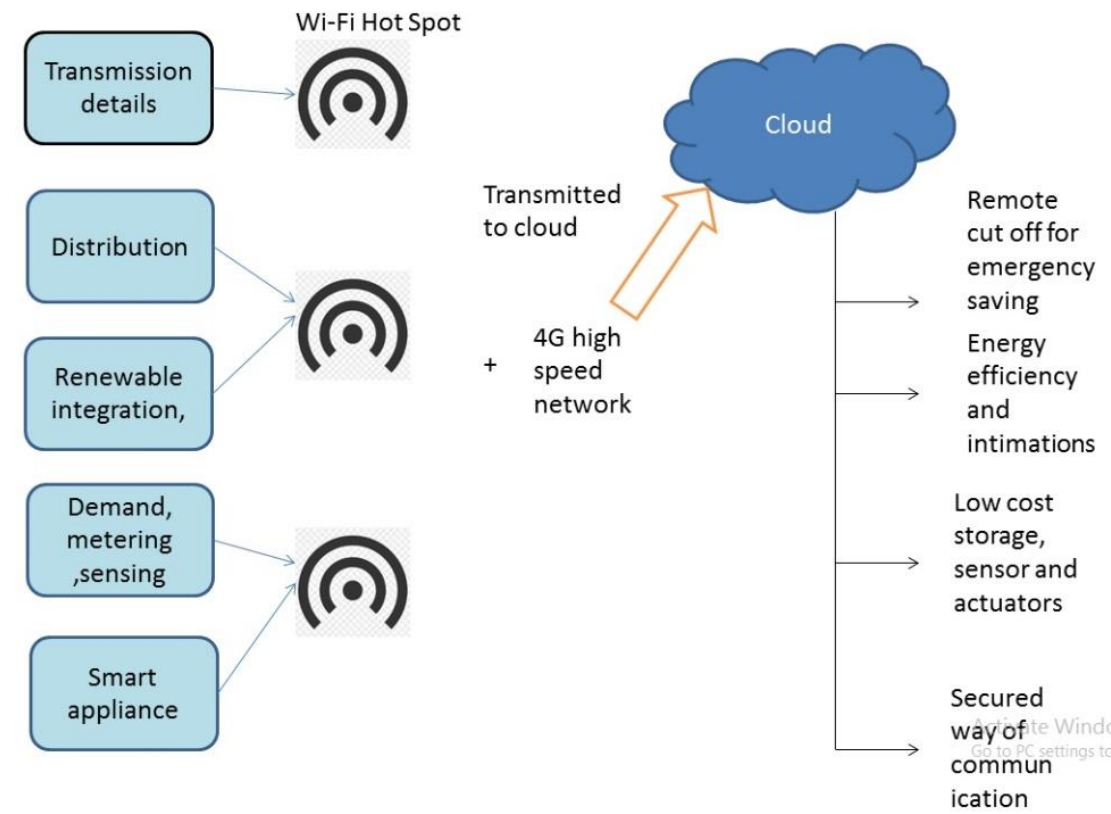

Fig.3 Smart Grid Using Cloud

The fig . 3 shows the smart grid integration with the cloud service, the figure explains the complete take over by the cloud in handling the tasks of the smart grid in the managing the power distribution, generation, transmission, demand responses and the eluding of the mishandlings and the miscommunications. The proposed model utilizes the AWS EC2 in providing the cloud service for the perfect management in the smart grid eluding the overuse thus reducing the carbon emission and securing the information transmission. The information monitored and metered is conveyed through the Wi-Fi hotspots using the internet services (high speed 4G network) to the cloud. This serves as efficient method for the automated control and the commanding leading to a perfect management and storage of the energy by enhancing the device intelligence and decreasing the storage cost of the devices. As shown in the figure. 3 the information's about the transmission, distribution, generation, the demand responses required, monitored and the metered information's are sent to the cloud utilizing the Wi-Fi hotspots and the $4 \mathrm{G}$ high speed internet services. The cloud acts the controlling device or the decision maker, providing the automated control over the smart grid and generating commands to the for cutting down the enormous use of the electricity in the house hold activities whenever there is a peak demand and providing an alternative way of energy supply when ever faced with the failures, the usage of the cloud enables to reduce the enormous power usage thereby reducing the carbon emission thus making the system sustainable. The cloud provides the security as service for the smart grids to protect the mishandlings in the two way communication. The AWS EC2 used provides with the more reliable way of communication with authentication avoiding the mishandlings and the misuse. Thus providing secured and a sustainable frame work for the Smart Grid. 
Journal of ISMAC (2019)

Vol.01/ No. 03

Pages: $137-146$

http://irojournals.com/iroismac/

DOI: https://doi.org/10.36548/jismac.2019.3.001

\section{RESULTS AND DISCUSSION}

The proposed system is validated by monitoring the continuous usage of the electricity in a residential area, with the smart grid supported by the cloud computing. The bill received from the electricity boards is gathered to monitor the electricity usage. Fig.4 shown below shows the reduced electricity usage leading to an efficient energy management provided by the cloud in the house hold utilities by causing a maximum reduction in the usage of the electricity thereby reducing the $\mathrm{Co}_{2}$ emission and making the smart grid sustainable.

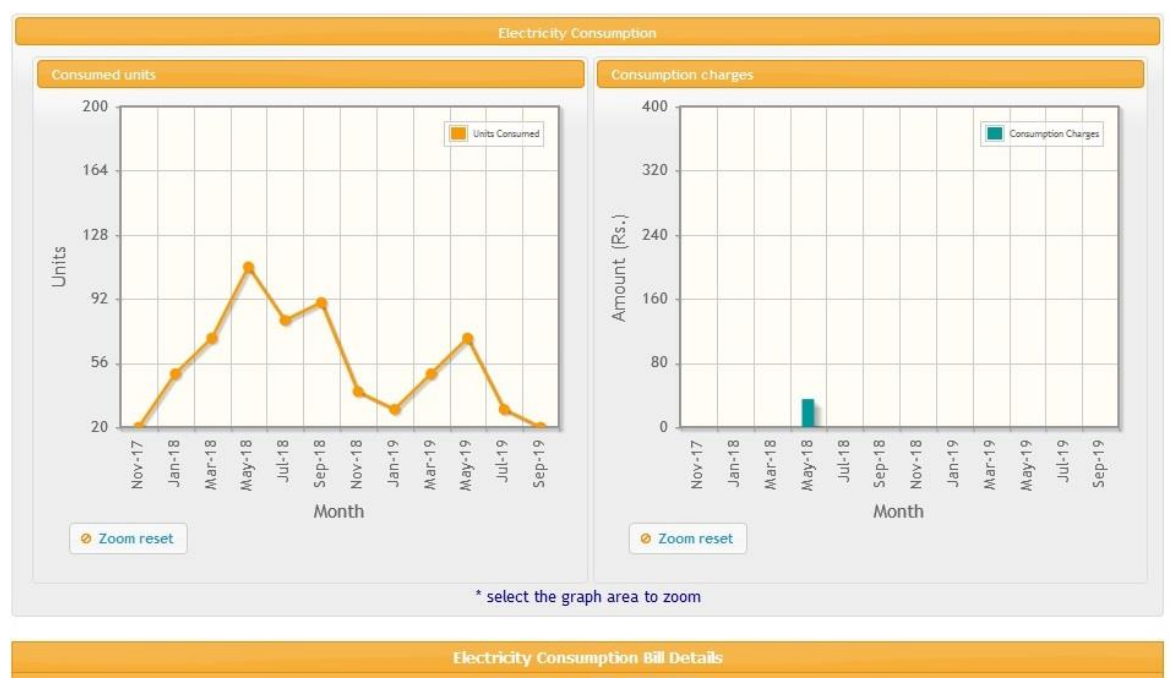

Fig .4 The Electricity Usage Report

This electricity bill obtained shown in the fig.4, providing the details of the consumed units and the charge per consumption enables the user to verify with the metered readings that are been monitored. The fig. 5 below provides a percentage of the sustainability and the security in the full duplex communication based on the monitoring of the power distribution, management and the security achieved over multiple usages. 
Journal of ISMAC (2019)

Vol.01/ No. 03

Pages: $137-146$

http://irojournals.com/iroismac/

DOI: https://doi.org/10.36548/jismac.2019.3.001

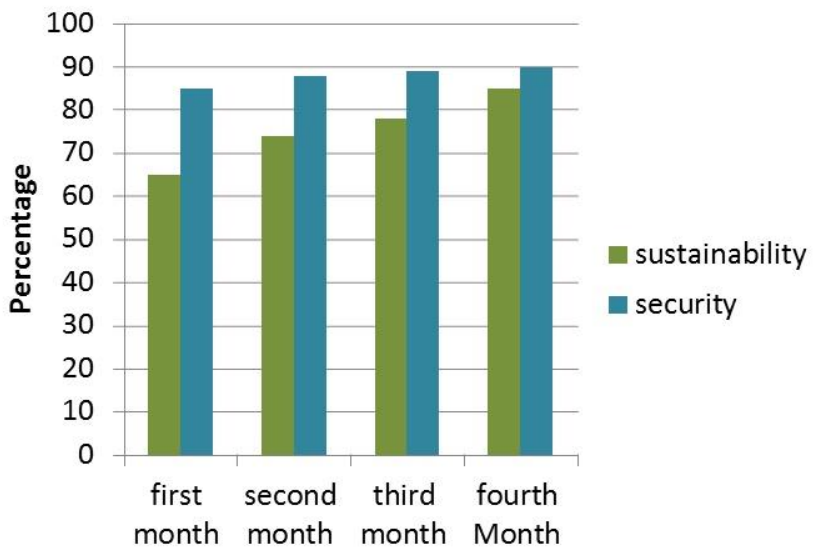

Fig .5 Percentages of sustainability and security

The fig .5 above shows the percentage of the sustainability and the security attained in electricity usage and the full duplex communication provided by the smart grid enabled by cloud.

\section{CONCLUSION}

The proposed method for the smart grid to have a sustainability and security using the cloud computing, involves the utilization of the Wi-Fi hotspot in gathering the information's based on the usage by the monitoring and metering. The information gathered is conveyed to the cloud using the high speed- $4 \mathrm{G}$ networks. The cloud computing takes control over all areas of the smart grid from power generation, transmission, demand response to distribution by providing a fully automated control and commands for managing the electricity usage to improve the sustainability and enhance the security of the smart grid. The evaluation of the proposed system by collecting the information's of the electricity usage, power distribution, management and the security achieved over multiple usages show that the proposed method shows an improved sustainability and security for the Smart Grids.

\section{REFERENCES}

[1] Fang, Xi, Satyajayant Misra, Guoliang Xue, and Dejun Yang. "Smart grid-the new and improved power grid: A survey." IEEE communications surveys \& tutorials 14, no. 4 (2011): 944-980. 
Journal of ISMAC (2019)

Vol.01/ No. 03

Pages: $137-146$

http://irojournals.com/iroismac/

DOI: https://doi.org/10.36548/jismac.2019.3.001

[2] Gungor, Vehbi C., Dilan Sa

[3] hin, Taskin Kocak, Salih Ergut, Concettina Buccella, Carlo Cecati, and Gerhard P. Hancke. "Smart grid technologies: Communication technologies and standards." IEEE transactions on Industrial informatics 7, no. 4 (2011): 529-539.

[4] McDaniel, Patrick, and Stephen McLaughlin. "Security and privacy challenges in the smart grid." IEEE Security \& Privacy 7, no. 3 (2009): 75-77.

[5] Khurana, Himanshu, Mark Hadley, Ning Lu, and Deborah A. Frincke. "Smart-grid security issues." IEEE Security \& Privacy 8, no. 1 (2010): 81-85.

[6] Amin, S. Massoud, and Bruce F. Wollenberg. "Toward a smart grid: power delivery for the 21st century." IEEE power and energy magazine 3, no. 5 (2005): 34-41.

[7] Farhangi, Hassan. "The path of the smart grid." IEEE power and energy magazine 8, no. 1 (2009): 18-28.

[8] Bayindir, Ramazan, I. Colak, G. Fulli, and K. Demirtas. "Smart grid technologies and applications." Renewable and Sustainable Energy Reviews 66 (2016): 499-516.

[9] Tuballa, Maria Lorena, and Michael Lochinvar Abundo. "A review of the development of Smart Grid technologies." Renewable and Sustainable Energy Reviews 59 (2016): 710-725.

[10] Hayes, Brian. "Cloud computing." Communications of the ACM 51, no. 7 (2008): 9-11

[11]Buyya, Rajkumar, Chee Shin Yeo, Srikumar Venugopal, James Broberg, and Ivona Brandic. "Cloud computing and emerging IT platforms: Vision, hype, and reality for delivering computing as the 5th utility." Future Generation computer systems 25, no. 6 (2009): 599-616.

[12]Zhang, Qi, Lu Cheng, and Raouf Boutaba. "Cloud computing: state-of-the-art and research challenges." Journal of internet services and applications 1, no. 1 (2010): 7-18.

[13] JoSEP, Anthony D., RAnDy KAtz, AnDy KonWinSKi, L. E. E. Gunho, DAViD PAttERSon, and ARiEL RABKin. "A view of cloud computing." Communications of the ACM 53, no. 4 (2010). 